Journal of Advanced College of Engineering and Management, Vol. 3, 2017

\title{
ECONOMIC EXTENSION OF TRANSMISSION LINE IN DEREGULATED POWER SYSTEM FOR CONGESTION MANAGEMENT
}

\author{
Pravin Kumar
}

Email Address: pravin.kumar@ntc.net.np

\begin{abstract}
The chances of congestion in deregulated market are quite high as compared to the monopolistic market as the customers would like to purchase electricity from cheapest available sources. Ways for Congestion management are: Generation rescheduling, Interruptible load curtailment, Transmission system expansion etc. Transmission expansion planning is the last way for congestion management if congestion is not managed by Generation rescheduling and Interruptible load curtailment. A high mean of Locational marginal price (LMP) at a bus indicates no access to cheap generation and a low mean of LMP indicates access to excess cheap generation and no access to enough loads. Hence, constructing a new line between two buses with low and high mean of LMP will allow the dispatch of the excess cheap generation and flow of energy from low LMP bus to high LMP bus due to price potential difference. Consequently, the flatness of price profile is improved. The final plan is selected by economic analysis.
\end{abstract}

Keywords: Deregulated power market, Locational marginal price, congestion, Generator Company (GENCO), Transmission Company (TRANSCO), Distribution company (DISCO), System operator (SO).

\section{Introduction}

Deregulation in power industry is a restructuring of rules and economic incentives that government sets up to control and drive the electric power industry. As electric loads and generation grow, transmission expansion planning should be carried out in timely and proper way to facilitate and promote competition.

In deregulated power systems participants take their decisions independently. They change their strategies frequently to acquire more information from the market to maximize their benefits. Consumers adjust their loads according to the price signals. In deregulated power system, there are choices of GENCO for DISCO, consumer; based on their bidding price, reliability, power quality and mutual agreement. In order to deliver the power from GENCO to DISCO, transmission line is used. So that the power flow from transmission line also depends upon market participant choice. The scarcity of transmission capacity and a continuous demand for power from less expensive sources lead to transmission system congestion.

\section{Marginal cost}

Marginal cost is the cost of supplying next MW of load at a specific location. It is important characteristic of a generator. It is a measure of how costly it will be to produce the next increment of power. For example, it may cost a generator $\$ 1000 / \mathrm{hr}$ to produce $1 \mathrm{MW}$ of power, but it does not cost $\$ 2000 / \mathrm{hr}$ to produce $2 \mathrm{MW}$. The marginal cost can be obtained from the derivative of cost function of generator $\left(\mathrm{C}\left(\mathrm{P}_{\mathrm{gi}}\right)\right)$ with respect to power generated by corresponding generator $\left(\mathrm{P}_{\mathrm{gi}}\right)$. In accordance to the theory of marginal costs, the marginal cost at bus i defined by eq ${ }^{\text {n: }}$

$$
(\mathrm{MC})_{\mathrm{i}}=\partial\left(\mathrm{C}\left(\mathrm{P}_{\mathrm{gi}}\right) / \partial \mathrm{P}_{\mathrm{gi}}\right.
$$

Where, $\mathrm{C}\left(\mathrm{P}_{\mathrm{gi}}\right)$ is the cost function of $\mathrm{i}^{\text {th }}$ generator.

\section{Congestion}

When the producers and consumers of the electric energy desire to produce and consume in amounts that would cause the transmission system to operate at or beyond one or more transfer limit, the 
system is said to be congested. Generator rescheduling and interruptible load curtailment are startup way for congestion management. Transmission expansion planning is the last way for congestion management if congestion is not managed by Generation rescheduling and Interruptible load curtailment. Congestion management is one of the most challenging tasks of the system operator in the deregulated environment.

\section{Algorithm}

The following algorithm is used:

1. Calculate the marginal cost of each bus by Powerworld Simulator software.

2. Calculate the daily congestion cost of each transmission line using eq ${ }^{\mathrm{n}}$ (4.1)

Congestion cost $=\mid\left(M C\right.$ of bus $i^{\text {th }}-M C$ of bus $\left.j^{\text {th }}\right) \mid$

* Power flow through ij transmission line

3. Calculate the yearly congestion cost of each transmission line using eq ${ }^{\mathrm{n}}(4.2)$

Yearly congestion cost of transmission line

$=$ Hourly congestion cost of transmission line $* 24 * 365$

4. Set a Specified value (SV) to compare with yearly congestion cost. Specified value is the value up to which congestion cost is allowed.

5. Compare the each yearly congestion cost with specified value (SV).

If yearly Congestion cost $\geq \mathrm{SV}$, then suggest constructing new transmission line parallel to existing transmission line which is indicated by 'Plan needed' otherwise indicated by 'OK'

6. Count the total number of transmission line extension plan for particular Specified value.

7. If number of transmission line extension plan is greater than 6 then increase specified value and go to step 5 .

If the limit of number plan for extension of transmission line is more then it leads towards more accurate plan for extension of line but also it becomes more complex and time consuming. If the system planners have sufficient time and money then they can suggest working on large number of plan. Due to limited time, for this thesis up to 6 number of plan is considered. As the process of analysis is same for large number of plan, so this algorithm also works for large number of plan by changing only in step 7 in which it should declared to maximum limit of plan.

8. Determine the most economical plan by economic analysis

\section{Economic analysis of plan}

i. Calculate the daily and yearly congestion cost after extension of transmission line by using $\mathrm{eq}^{\mathrm{n}}$ (4.1) and eq ${ }^{\mathrm{n}}$ (4.2).

ii. Calculate the total yearly congestion cost before and after extension of transmission line by using eq ${ }^{\mathrm{n}}(3)$

Total yearly congestion cost $=$

Sum of all yearly transmission line congestion cost ... (4.3)

iii. Calculate the decrease in annual congestion cost after extension of transmission line.

iv. Calculate the annual increase in transmission line cost after extension of transmission line.

v. Calculate the economic ratio

Economic ratio $=$

Annual decrease in congestion cost after extension of tranmissio line

Annual increase in transmission line cost after extension of transmission line 
vi. Compare the economic ratio and determine the highest economic ratio.

vii. The highest economic ratio means most economical plan for extension of transmission line which is desire output.

\section{Software Tool}

PowerWorld Simulator is used as software tool to calculate the bus marginal price and line flow by optimal power flow (OPF) analysis.

\section{Test system}

The IEEE 30 bus systems have 6 generators, 30 buses, 21 load buses and 41 transmission lines is shown in figure A.1. The generator data, load data and transmission line data are shown in appendix A. It is better to work on our Nepalese power system network but our system is not in deregulated. So, The IEEE 30 bus is used as test system.

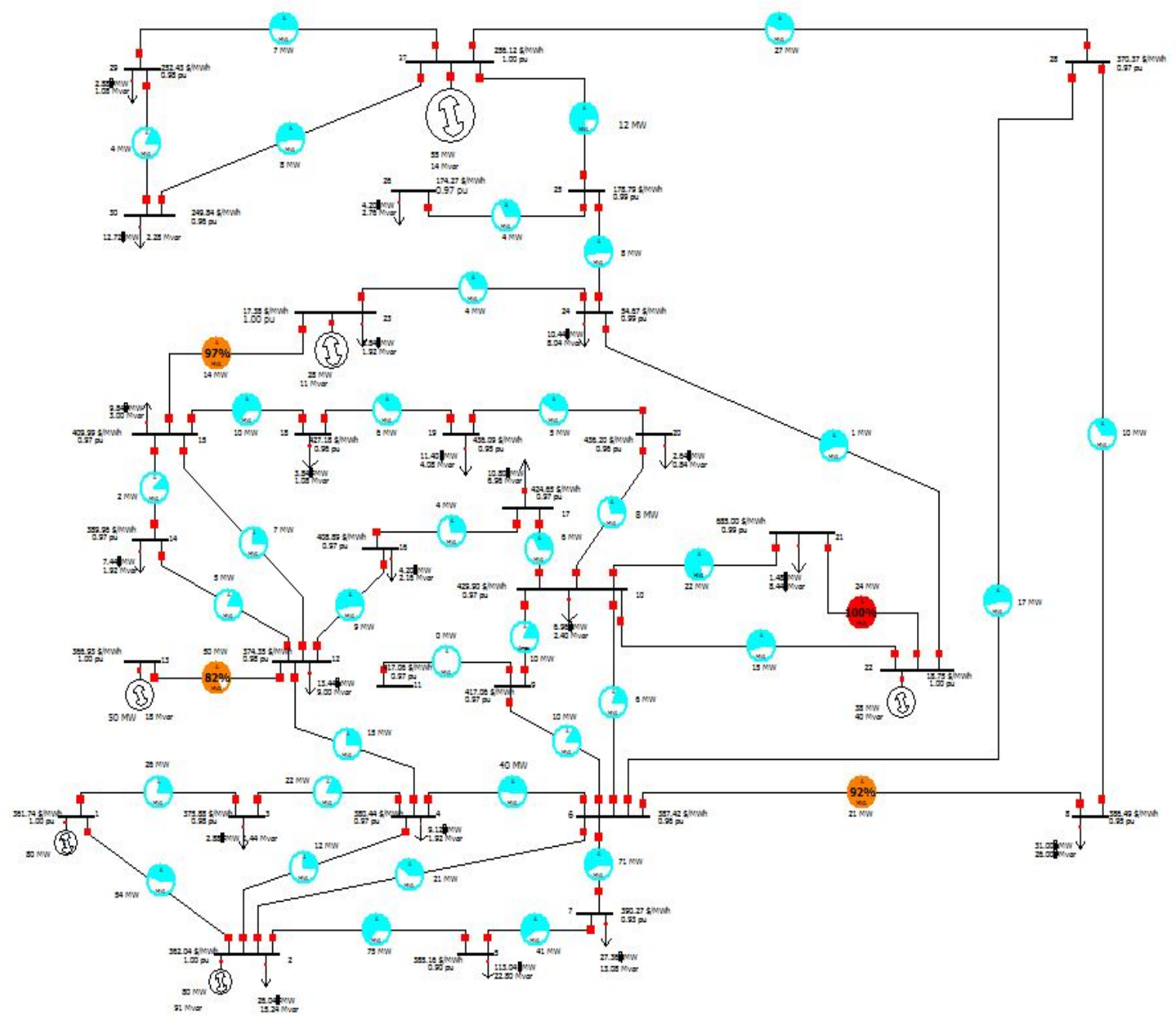

Fig 1 IEEE-30 bus system simulated in power world simulator

\section{Results and Discussions}

From the simulation results, the congestion cost of each line is calculated. The number of transmission line extension plans for different specified values (SV) is listed below: 
Table 1 Number of extensions of transmission line plan for different SV

\begin{tabular}{|c|c|c|c|c|c|}
\hline Specified value & $\begin{array}{c}\text { Congestion } \\
\text { Charge }> \\
\$ 5000\end{array}$ & $\begin{array}{c}\text { Congestion } \\
\text { Charge }> \\
\$ 50000\end{array}$ & $\begin{array}{c}\text { Congestion } \\
\text { Charge }> \\
\$ 500000\end{array}$ & $\begin{array}{c}\text { Congestion } \\
\text { Charge }> \\
\$ 1000000\end{array}$ & $\begin{array}{c}\text { Congestion } \\
\text { Charge }> \\
\$ 2000000\end{array}$ \\
\hline Number of plan & $\mathbf{3 8}$ & $\mathbf{2 3}$ & $\mathbf{6}$ & $\mathbf{5}$ & $\mathbf{4}$ \\
\hline
\end{tabular}

From above table it can be concluded that it is better to take specified value of $\$ 500000$ as it has suitable number of plans. But if the transmission system operator has sufficient time and money then he/she can work on higher number of plans for highly efficient performance of the line.

\section{Identification of plan}

For planning of transmission line $\mathrm{SV}$, is taken as $\$ 500000$. Name of plan for extension of transmission line parallel to corresponding lines are given below.

Table 2 Identification of plan

\begin{tabular}{|c|c|c|c|}
\hline $\begin{array}{c}\text { From } \\
\text { Bus }\end{array}$ & To Bus & $\begin{array}{c}\text { Line Congestion Cost } \\
\text { Per year(\$) }\end{array}$ & Plan \\
\hline 2 & 5 & 632910 & Plan 1 \\
\hline 10 & 21 & 2057764.2 & Plan 2 \\
\hline 10 & 22 & 2221032.3 & Plan 3 \\
\hline 15 & 23 & 2077888.4 & Plan 4 \\
\hline 22 & 21 & 5812031.9 & Plan 5 \\
\hline 27 & 28 & 1121763.6 & Plan 6 \\
\hline
\end{tabular}

\section{Economic analysis}

The extension of transmission line under different plan changes the marginal cost and congestion cost of transmission line which plan is the most economical plan among all of the plans is decided by economic analysis.

\section{Change in Congestion cost}

The yearly decrease in congestion cost and yearly increase in congestion cost is shown in Figure 2 . From this figure, it is clearly observe that plan 2 has lowest yearly decrease in congestion cost whereas Plan 1 has highest yearly decrease in congestion cost. From this figure, it is also clearly observe that Plan 1 has highest yearly increase in transmission line cost whereas Plan 4 has lowest yearly increase in transmission line cost. 


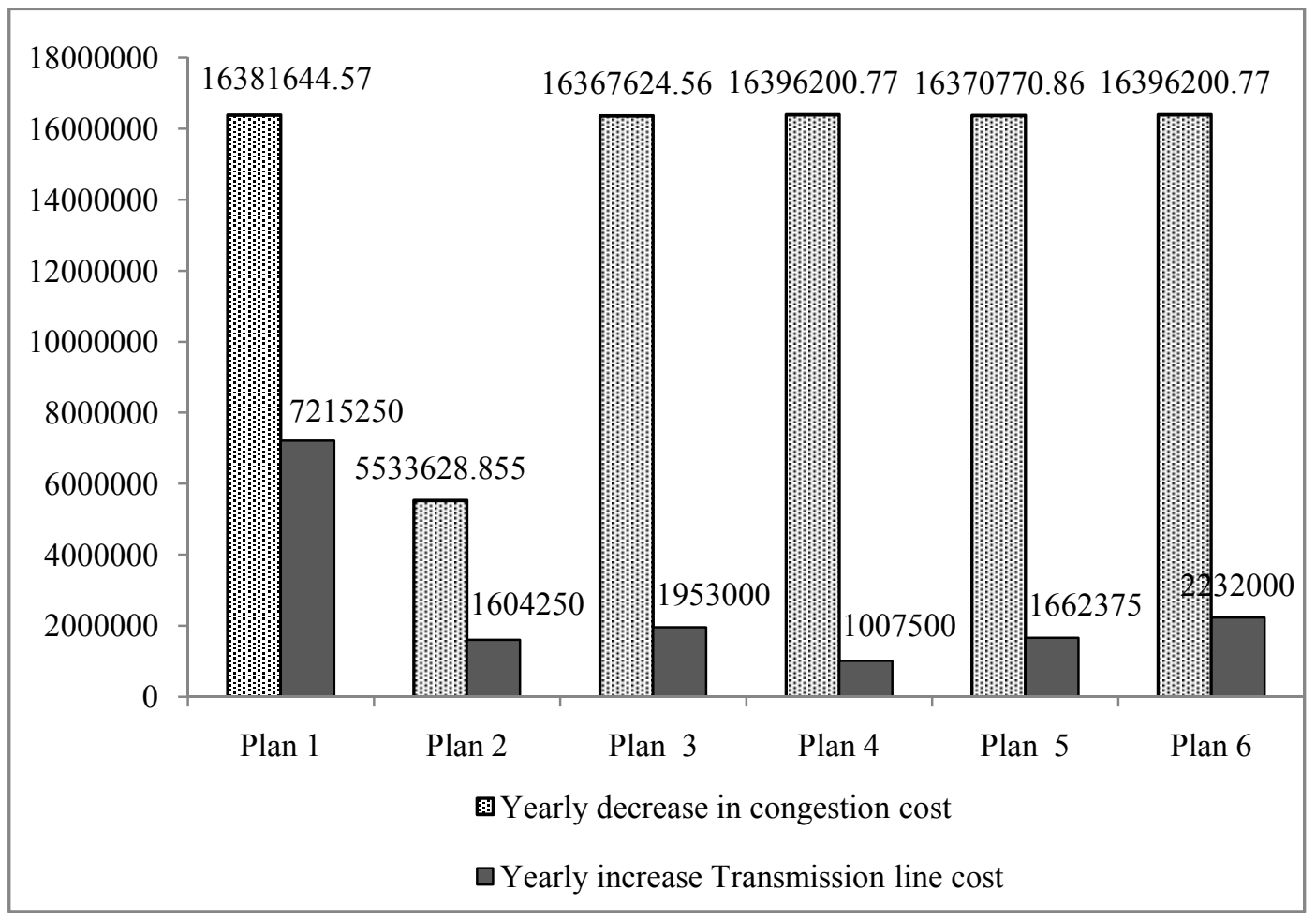

Fig 2 Chart diagram of change in congestion cost and change in transmission line cost

\section{Economic ratio}

After calculation of economic ratio of different Plans it is clear that in spite of same annual decrease in congestion cost, the economic ration may be different as shown in Fig 3. The economic ratio becomes high if decrease in annual congestion cost is high and increase in yearly transmission line cost is low.

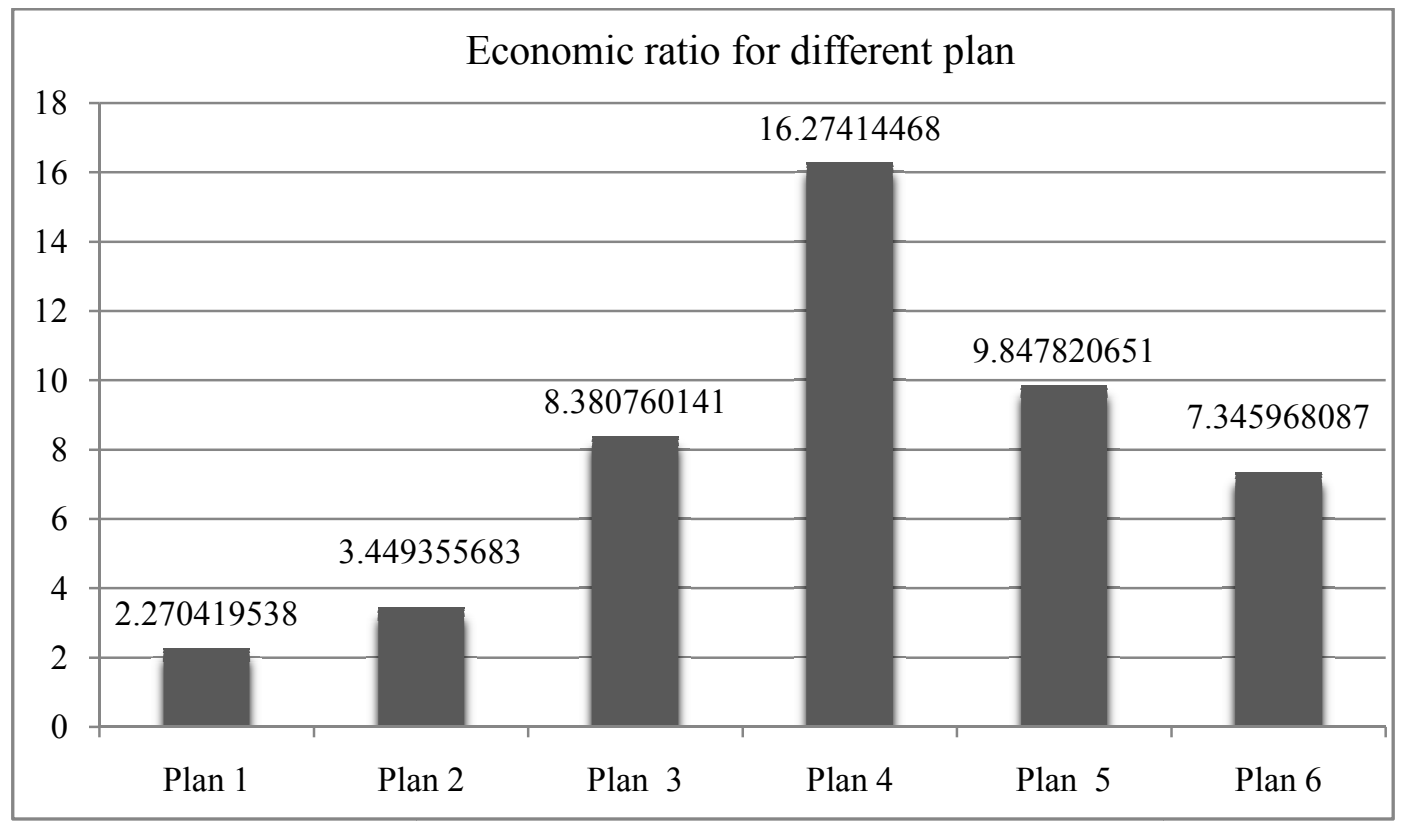

Fig 3 Chart diagram of economic ratio of different plan

Economic ratio of different plan is shown in Figure 3. From this figure it is clearly observe that Plan 1 has lowest economic ratio and Plan 4 has highest economic ratio i.e. Plan 4 gives more return with less investment than other plans. If economic ratio analysis is not considered there are conflicts in 
decision as there are Plan 1 has highest yearly decrease in congestion cost and also Plan 4 and Plan 6 creates conflicts in decision because they have same yearly decrease in congestion cost as shown in Figure 2.

From above it is concluded that Plan 4 has highest economic ratio so that the Plan 4 is most economical plan.

\section{Conclusions}

Constructing a new line between two buses with low and high mean of LMP allows the dispatch of the excess cheap generation and flow of energy from low LMP bus to high LMP bus due to price potential difference.

The specified value of congestion cost must be selected so that reasonable number of candidates is suggested. In the proposed method, when SV is Set as SV $=\$ 500000$ through hit and trial method, then there existed 6 number of transmission line extension plan. From the economic analysis, there is no congestion cost for either Plan 4 or Plan 6 . But from the economic ratio analysis of six different plans, Plan 4 has the highest economic ratio (16.2741) and hence needs to be implemented. Therefore, plan 4 is recommended for construction from bus 15 to 23 which has the highest economic ratio. The recommended plan, if implemented, increases the transmission cost $\$ 1007500$ per year but decrease the congestion cost by $\$ 16396200.77$ per year providing great platform for power market.

\section{Recommendations for further study}

During the course of study, following recommendations are proposed for further research:

1. The study is done on IEEE 30 test bus system. For further work it is recommended to do on real de-regulated power system of a particular country/area.

2. Flat variations on each load are considered at one time. For further work it is recommended to do the variation on load by combination variation of load.

\section{References}

1. Buygi Majid Oloomi, Member "Market-Based Transmission Expansion Planning" IEEE Transaction on power system, Vol. 19, NOV 2004

2. $\mathrm{Xu}$ Zhao, "A Hybrid Planning method for transmission networks in De-regulated environment" IEEE Transaction on power system, Vol. 21, May 2006

3. "PowerWorld Simulator Version 7.0 User's Guide", Power World Corporation, October 2000.

4. Miller R. H. and Malinowski J. H., "Economic Operation of Power Systems”, Power System Operation, 3rd Edition, McGraw-Hill, New York, 1970, pp. 63-82.

5. Saadat H., "Power System Analysis", McGraw-Hill, Boston, 1999.

6. Grainger J. J. and Stevenson W. D., "Power System Analysis", McGraw-Hill, New York, 1994. 